\title{
Refuncionalização de fazendas de café a partir da atividade turística em Campinas (SP)
}

\section{Refunctionalization of coffee farms based on tourist activities in Campinas (SP)}

\author{
Gabriela Couto Barbosa ${ }^{1}$, André Munhoz de Argollo Ferrãoº \\ 1 - Doutoranda no Programa de Pós-Graduação em Ensino e História de Clências da Terra (PPG-EHCT), Universidade Estadual de Campinas. Caixa Postal 6152, \\ 13083-855, Campinas, SP, Brasll. \\ 2 - Docente do Programa de Pós-Graduação em Ensino e História de Ciências da Terra (PPG-EHCT), Faculdade de Engenharia Civil e Arquitetura, Universidade \\ Estadual de Campinas. Caixa Postal 6152, 13083-855, Campinas, SP, Brasil. Pesquisador CNPQ. \\ E-MAIL: GABRIELA.COUT025@GMAll.COM, ARGOLLO@UNICAMP.BR
}

\begin{abstract}
Tourism is an activity that interacts with different sectors of society, such as culture, sports and the Citation/Citação: Barbosa, G. C., environment. This makes it present in people's daily lives, many times, without realizing its importance. However, \& Argollo Ferrão, A. M. (2020). tourism does not have a single mode of operation, and ends up appropriating elements used by other sectors, such Refuncionalização de fazendas as agriculture, for example. The present work seeks to analyze some examples of coffee farms that have undergone a process of refunctionalization and became tourist attractions. Campinas is part of a very important region in the history of coffee production, particularly when it comes to the period of expansion of coffee growing in Brazil, and still retains some elements that show this history. Not all coffee farms have undergone a refunctionalization process. In addition, of the examples that went through this process, not all were successful, as is the case of Fazenda Jambeiro. It is concluded, therefore, that the refunctionalization of coffee farms by tourism can assist in the process of preservation and conservation of such places, besides helping to disseminate the history of municipalities that have a strong link with coffee growing, which, in general, is not recognized by its own inhabitants. Refuncionalização de fazendas rística em Campinas (SP). Terræ Didatica, 16, 1-7, e020023. doi: 10.20396/td.v16i0.8657347

Keywords: Coffee. Cultural heritage. Rural tourism.
\end{abstract}

Resumo: 0 turismo é uma atividade que interage com diferentes setores da sociedade, como cultura, esporte e meio ambiente. Isso 0 torna presente no cotidiano das pessoas, muitas vezes, sem que se perceba a sua importância. Entretanto, o turismo não possui um único modo de operação e acaba se apropriando de elementos utilizados por outros setores, como a agricultura, por exemplo. 0 presente trabalho tem como objetivo analisar alguns exemplos de fazendas de café que passaram por um processo de refuncionalização e se tornaram atrativos turísticos. Campinas faz parte de uma região muito importante na história da produção de café, particularmente em se tratando do período de expansão da cafeicultura no Brasil, guardando alguns elementos que mostram essa história. Há que se ressaltar que nem todas as fazendas de café passaram por um processo de refuncionalização. Além disso, dos exemplares que passaram por esse processo, nem todos tiveram sucesso, como é o caso da Fazenda Jambeiro. Conclui-se, portanto, que a refuncionalização das fazendas de café pelo turismo pode auxiliar no processo de preservação e conservação de tais locais, além de auxiliar na divulgação da história dos municípios que possuem um forte vínculo

Palavras-chave: Café. Patrimônio cultural. Turismo rural.

Manuscript/Manuscrito:

Received/Recebido: 20/01/2020

Revised/Corrigido: 08/05/2020

Accepted/Aceito: 29/05/2020

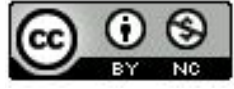
com 0 café e que, em geral não é reconhecido por seus próprios cidadãos.

\section{Introdução}

As fazendas de café constituem elementos significativos do patrimônio cultural brasileiro, especialmente em se tratando da região Sudeste. Mas nem sempre foi assim. Até o final do século XVIII, início do século XIX, a economia do Brasil esteve ligada principalmente a grandes produções de cana-de-açúcar, localizadas principalmente na região Nordeste (Benincasa, 2007). A partir do final do século XVIII o café paulatinamente passa a ter uma importância cada vez mais significativa na economia do Brasil-colônia, tornando-se o principal produto do Império, ao longo de todo o séculoXIX, com destaque à região Sudeste, principal produtora.
Atualmente as fazendas cafeeiras não possuem as mesmas características que apresentavam no período áureo da cafeicultura brasileira (segunda metade do século XIX e primeira metade do século $\mathrm{XX}$ ), não só em relação ao modelo de produção, mas também no que tange à sua estrutura. Os grandes casarões e as construções complementares ao fabuloso conjunto arquitetônico deram lugar a plantações, em alguns casos, com considerável aporte tecnológico de um bom maquinário exercendo grande parte das atividades e das funções no campo, ou então sem esse aporte, porém em glebas de tamanhos menores, mais adequados ao contexto de cada região produtora. 
Nesse cenário, as antigas fazendas de café ganham um novo significado dentro do espaço que ocupam e passam a exercer outra função na dinâmica social e econômica da região onde estão inseridas: a função de atrativo turístico.

O objetivo deste trabalho é entender como as fazendas de café, que já foram importantes figuras da economia campineira, foram apropriadas por outras atividades e ganharam um novo significado dentro do cenário econômico, sem perder sua história e parte de suas características enquanto área produtora de café.

\section{Uma breve contextualização do café em São Paulo}

A versão mais aceita atualmente sobre a entrada do café no Brasil diz que esse processo ocorreu na região Norte, trazido da Guiana Francesa pelo sargento-mor Vicente de Melo Palheta, que trouxe algumas mudas e algumas sementes (Rufino, 2006). Posteriormente acabou se adaptando ao território brasileiro ao final do século XVIII na região Sudeste, após diversas tentativas mal sucedidas de implantação na região Nordeste. Rufino (2006) afirma que a introdução do café no Brasil se deu em um contexto de fortes disputas comerciais e que o café já era visto como um produto possivelmente estratégico.

A expansão do café no Brasil e o aumento da sua importância para a economia auxiliaram na melhoria da infraestrutura no Brasil, especialmente na região Sudeste, com a criação de estradas de ferro e do Porto de Santos (Rodrigues, Dias e Teixeira, 2015).

A primeira plantação de café em uma escala considerável no Brasil estava localizada no Rio de Janeiro e teve como responsável o médico francês Louis François Lecesne (Argollo Ferrão, 2015). Entretanto, a primeira fazenda de café está relacionada ao padre Antônio do Couto da Fonseca, como apresenta Argollo Ferrão (2015):

O padre Antônio do Couto da Fonseca, antigo lavrador de cana e anil, no Mendanha (freguesia do Campo Grande), passou a cultivar café, a partir de 1780. É de fato a quem se deve a abertura da primeira fazenda de café, digna desse nome, no Brasil. (Argollo Ferrão, 2015, p.49).

Não há uma data exata para a chegada do café em São Paulo, porém, acredita-se que tenha ocorri- do por volta de 1795 (Argollo Ferrão, 2015). Entretanto, é de conhecimento comum que a cultura do café possui enorme importância histórica para o estado de São Paulo, uma vez que o seu desenvolvimento econômico se deve ao café.

Benincasa (2007) afirma que até meados do século XVIII a região Sudeste não possuía grande importância em relação à produção agrícola, uma vez que a cana ainda dominava na região Nordeste. Porém, a Corte Portuguesa passa a prestar maior atenção à fertilidade das terras mais ao sul visando produtos como a cana e posteriormente o café. A partir daí, São Paulo paulatinamente aumenta a sua expressividade em relação à produção agrícola. $\mathrm{O}$ processo não foi tão simples e fácil, principalmente por parte dos produtores. Havia certa resistência em introduzir um novo produto. Somente quando o açúcar deixou de ser um produto com mercado garantido internacionalmente é que o café passou a ser visto como uma opção viável (Benincasa, 2007).

Tendo entrado no final do século XVIII pelo Vale do Paraíba, o café se expandiu por grande parte do território paulista a partir do século XIX, incluindo Campinas, que se destacou como a principal região produtora do Império no último quartel daquele século. A região de Campinas foi efetivamente importante para o desenvolvimento da cultura cafeeira, não somente pela pujança dos produtores, mas também pelo cenário propício para investimentos em ciência e tecnologia aplicados ao café.

A crise econômico-financeira de 1929 assumiu proporções globais quebrando muitos fazendeiros de café no Brasil. A retomada ocorreu com a ascensão de novos produtos e a diversificação da economia, levando o café a perder o seu protagonismo de principal produto de exportação do País. Assim, São Paulo deixa de ser um estado exclusivamente produtor de café para se tornar industrial e policultor. Muitas fazendas passaram por uma transição estrutural refletindo mudanças em seus produtos e técnicas de produção, entretanto há aquelas que conservaram muitos dos seus elementos e características arquitetônicas do período áureo da cultura cafeeira. Para essas fazendas, resta uma dúvida: como se readaptar em um espaço moderno e tecnológico sem perder a essência?

\section{Refuncionalização e o turismo}

As mudanças rápidas e complexas que ocorreram no mundo a partir da Revolução Industrial e 
da globalização obrigaram alguns espaços e atividades a se reinventarem. Nesse sentido, a Geografia adotou um novo conceito para esse fenômeno: a refuncionalização, que consiste no ato de atribuir outra função a algo ou a determinado espaço. $\mathrm{O}$ processo pode ocorrer de diferentes formas e em diferentes escalas. Uma das atividades que mais se beneficia é o turismo. É comum a existência de atrativos turísticos que foram ressignificados pela história, como antigos casarões, fortes, castelos, edifícios industriais etc., e também: fazendas de café.

Considerando que muitas fazendas de café localizadas em Campinas não atuam mais como produtoras, houve necessidade de adaptação estrutural e refuncionalização do espaço. Nesse aspecto o turismo se faz presente como uma opção viável e importante.

Deve-se considerar que há diversas maneiras de entender o turismo. O espaço da prática turística pode ser interpretado e apropriado de diferentes formas, a depender de quem o faz. No caso das fazendas de café é comum que o turismo praticado em suas dependências seja diretamente ligado à presença de elementos rurais, muitas vezes de aspecto bucólico, e que remetam ao passado colonial brasileiro. Porém, uma fazenda de café pode proporcionar bem mais do que os tão comuns elementos bucólicos e em alguns casos os cafés da manhã coloniais. A fazenda de café pode apresentar a oportunidade de uma experiência empírica de retomada de parte do passado brasileiro, levando o turista a observar in situ como aquele sistema funcionou.

O turismo tem crescido de forma significativa no Brasil. Somente no ano de 2018, 8,1\% do produto interno bruto (PIB) brasileiro foi originado com o turismo, de acordo com o World Travel and Tourism Council - WTTC (2019). Houve um crescimento da atividade turística no Brasil de aproximadamente $3,9 \%$, acima da média mundial que foi de 3,2\% (WTTC, 2019).

De acordo com Rodrigues (1997), o turismo deve ser entendido como um fenômeno não só econômico, mas social, político e cultural e com importantes impactos ambientais. A Organização Mundial do Turismo (OMT, 1994) define turismo como:

las actividades que realizan las personas durante sus viajes y estancias en lugares distintos al de su entorno habitual, por un período de tiempo consecutivo inferior a un año con fines de ocio, por negocios y otros motivos no relacionados con el ejercicio de una actividad remunerada en el lugar visitado (OMT, 1994, p. 05).

Beni (2004) define turismo como sendo um fenômeno social que, ao originar uma série de atividades, como transporte, alojamento, recreação e outras, as fazem gerar uma série de efeitos sobre o meio ambiente em que se desenvolvem e que podem ser de caráter econômico, social, cultural ou ecológico. Considerando as diferentes caracterizações do turismo, observa-se em comum a presença de três elementos-chave: espaço físico, tempo e indivíduo.

O Ministério do Turismo (MTur) classifica a atividade turística em 12 categorias: turismo social, turismo cultural, turismo de estudos e intercâmbio, turismo de esportes, turismo de pesca, turismo náutico, turismo de aventura, turismo de sol e praia, turismo de negócios e eventos, turismo rural, turismo de saúde e ecoturismo (Brasil, 2014). Para uma melhor compreensão de tal atividade cabe uma breve revisão sobre essa classificação. No caso das fazendas de café, a prática turística pode ser enquadrada em três categorias: turismo cultural, ecoturismo e turismo rural.

Para o Ministério do Turismo (Brasil, 2014), toda viagem é uma experiência cultural, uma vez que ao sair do seu local de origem, o turista entra em contato com diferentes culturas. Entretanto, o que diferencia essa categoria é a motivação da viagem, pois nem todo turista é um turista cultural. Muitas vezes não há interesse por parte do turista nos aspectos culturais do local visitado. $\mathrm{O}$ turismo cultural começou na Europa a partir do período do Renascimento, quando os aristocratas se deslocavam para conhecer e apreciar locais que inspiravam obras de artistas famosos (Brasil, 2014). Desde então, a cultura continua sendo uma das principais motivações de turistas na hora de escolher um local para visitar.

O conceito de turismo cultural, portanto, de acordo com o MTur consiste em: "atividades turísticas relacionadas à vivência do conjunto de elementos significativos do patrimônio histórico e cultural, valorizando e promovendo os bens materiais e imateriais da cultura" (Brasil, 2014, p. 13).

Tal categoria apresenta uma divisão interna, a partir da qual surgem mais quatro subcategorias de turismo (Brasil, 2014): o turismo cívico, que tem a ver com fatos e acontecimentos relacionados com a Pátria, como visitar Brasília [DF]; o turismo 
religioso, prática turística relacionada com a busca de espiritualidade ou com a prática religiosa, como os romeiros em Aparecida (SP) ou os devotos do Padre Cícero em Juazeiro do Norte [CE], ou ainda, os participantes do Círio de Nazaré em Belém [PA]; o turismo místico ou esotérico, que também está ligado à busca da espiritualidade e do autoconhecimento, porém desvinculado das religiões tradicionais, como em São Tomé das Letras [MG] ou Pirenópolis [GO]; e o turismo étnico, que está ligado à prática de atividades por meio da vivência com grupos étnicos, como as aldeias indígenas, por exemplo, os Pataxós em Santa Cruz Cabrália [BA], ou ainda, os tradicionais cenários ou eventos relacionados com imigrantes no sul do País, como em Pomerode ou Blumenau [SC].

Em relação ao Ecoturismo, de acordo com o MTur, o termo surgiu na década de 1980 em consequência de um aumento mundial de valorização do meio ambiente. No Brasil, esse conceito passou a ser utilizado depois de 1994, quando o termo turismo ecológico foi substituído. (Brasil, 2014). Para compreender melhor tal conceito criou-se a seguinte definição:

Um segmento da atividade turística que utiliza, de forma sustentável, o patrimônio natural e cultural, incentiva sua conservação e busca a formação de uma consciência ambientalista através da interpretação do ambiente, promovendo o bem-estar das populações (Brasil, 2014, p 09).

A palavra sustentabilidade remete a uma relação harmoniosa entre os praticantes de uma determinada atividade ecoturística e os atrativos visitados. Nesse caso, busca-se um equilíbrio entre os interesses de tais praticantes, a necessidade de preservação da área visitada e o respeito à comunidade local para que tais práticas sejam consideradas adequadas ao ecoturismo. O MTur afirma que o ecoturismo tem sido o principal responsável pela introdução de práticas sustentáveis no turismo (Brasil, 2014).

Sobre o Turismo Rural, o MTur (Brasil, 2014) apresenta que a prática de visitação a áreas rurais no Brasil já acontece há muitos anos, porém apenas a partir da década de 1980 ela foi classificada da maneira como está atualmente. No Brasil, o turismo rural teve o seu início nos estados de Santa Catarina e Rio Grande do Sul, que resolveram proporcionar a diversificação das atividades econômicas de suas propriedades rurais. Por definição, turismo rural é "o conjunto de atividades turísti- cas desenvolvidas no meio rural, comprometido com a produção agropecuária, agregando valor a produtos e serviços, resgatando e promovendo o patrimônio cultural e natural da comunidade" (Brasil, 2014, p.49).

Caetano (2006) afirma que a atividade turística pode gerar benefícios significativos para uma localidade, como: geração de renda e divisas a partir da comercialização de produtos turísticos; geração de empregos; resgate e preservação dos valores socioculturais; distribuição de renda; redução do êxodo rural com o desenvolvimento do turismo em áreas rurais e contribuição para a preservação da fauna e da flora em áreas de proteção ambiental. Esses e outros fatores fazem da atividade turística uma oportunidade de desenvolvimento para qualquer região potencial, particularmente para aquelas que abrigam antigas fazendas de café nos estados do Sudeste (São Paulo, Minas Gerais, Rio de Janeiro e Espírito Santo).

É muito importante que a atividade turística conte com o apoio da população e do local em que é praticada, e que aconteça de forma sustentável e consciente, garantindo a conservação do patrimônio e a valorização da história da região. Visitar uma fazenda de café é como visitar um museu, com suas obras e histórias: É verificar, na prática, toda a história que foi contada outrora em sala de aula ou lida em livros. É andar por espaços que já foram habitados por imigrantes cheios de sonhos e por escravos cheios de desejo de liberdade. Portanto, conclui-se que a experiência de visitar uma fazenda de café é tão ampla que pode proporcionar ao turista uma viagem aos anos de ouro da produção cafeeira local.

\section{Campinas e suas fazendas de café}

Rufino (2006) afirma que "Campinas foi a porta de entrada do café no Oeste Paulista e a primeira cidade a cultivá-lo com base em um novo modelo de exploração, pautado no uso da mão de obra assalariada." (Rufino, 2006, p. 31). Rufino (2006) aponta ainda que no ano da Proclamação da República (1899), Campinas contava com cerca de 278 propriedades produtoras de café e gerava emprego para cerca de 25 mil trabalhadores.

Portanto, nota-se que Campinas foi uma região muito importante para a produção cafeeira no Estado de São Paulo. Por isso, apresenta ainda hoje alguns exemplares de fazendas que se mantiveram preservadas e que passaram por um processo de 
apropriação e de refuncionalização em seu espaço, transformando o que era utilizado na produção agrícola em um espaço turístico.

De acordo com Benincasa (2007), o café chegou ao município por volta dos anos 1830 . Nessa época, o produto estava em expansão em todo território brasileiro, em especial no território paulista. Silva (2006) afirma que a cana progrediu em Campinas até 1836 e a partir daí o café dominou a produção.

Campinas apresentava, de acordo com Benincasa (2007), um conjunto de características que favoreciam a produção cafeeira. O terreno plano, uma importante rede de cidades produtoras de café interligadas por estradas de terra e estradas de ferro, o solo fértil e a presença de mão de obra foram fatores essenciais para o sucesso do café na região.

A produção cafeeira em Campinas foi tão grande e importante, que se criou uma estrutura de ciência e tecnologia voltada para a melhoria da produção (Argollo Ferrão, 2015, 2004), como o Instituto Agronômico de Campinas. O IAC, como ficou conhecido o Instituto, teve sua criação aprovada pela Lei Orçamentária 3.314 de 16 de outubro de 1886, final do Brasil Império. Porém, sua fundação oficial se deu somente em 27 de junho de 1887, pelo então imperador Dom Pedro II (Ramos E Piacente, 2016). Benincasa (2007) afirma ainda que:

Campinas é local onde foram produzidas e exportadas as matrizes de quase todas as plantações paulistas nas zonas que ainda seriam desbravadas ao longo do século XIX e do século XX (Benincasa, 2007, p. 113).

A partir do declínio do café na região de Campinas, as fazendas que outrora foram tão importantes, perdem sua função precípua e passam por um processo de refuncionalização e de fragmentação (subdivisão em propriedades menores). Em alguns casos, essa refuncionalização se deu por meio do turismo.

Davi Martin, funcionário de um dos setores responsáveis pelo turismo na Prefeitura Municipal de Campinas, em entrevista a Gabriela Barbosa, informou que atualmente existem algumas fazendas de café na região, entretanto duas delas são especificamente voltadas ao turismo (ainda que se mantenham produtoras de café): a Fazenda Tozan e a Fazenda das Cabras (Martin, 2019). Há ainda outros exemplos como a Fazenda Andorinhas, antigo hotel fazenda, que atualmente se encontra fechado, e a Fazenda Jambeiro, patrimônio tomba- do pelo Conselho de Defesa do Patrimônio Artístico e Cultural de Campinas (CONDEPACC) e que atualmente se encontra abandonada entre ruas e casas no bairro que leva o seu nome: o Parque Jambeiro.

Tentou-se contato com as duas fazendas indicadas pelo setor responsável pelo Turismo em Campinas, porém nenhuma das duas permitiu visitação. Portanto, as informações apresentadas neste artigo foram retiradas de sites oficiais das fazendas e sites de turismo na internet.

\section{Fazenda das Cabras}

A Fazenda das Cabras passou a existir após a divisão da Sesmaria Sertão. Originalmente se identificava como uma fazenda de criação de gado, mas se tornou produtora de café no século XIX. De acordo com o sites oficial da fazenda:

Em 1877, foram construídos o núcleo industrial e outras edificações vinculadas a produção cafeeira: tulha, casa de máquinas e armazéns. A casa sede foi erguida em 1883 e seu requinte colonial perdura até os dias de hoje. (Fazenda Das Cabras, 2011).

Atualmente, a fazenda trabalha principalmente com eventos, como confraternizações, casamentos, eventos corporativos etc. Apesar de não ser um patrimônio tombado, os responsáveis pela fazenda fazem um trabalho bastante rigoroso e sério de preservação da área, tanto da área construída como da área verde. A área da fazenda está inserida na área de proteção ambiental (APA) da região de Sousas e Joaquim Egídio.

\section{Fazenda Tozan}

Originalmente, a Fazenda Tozan era conhecida como Fazenda Ponte Alta e foi fundada em 1798. Sua principal atividade econômica era a produção de cana de açúcar, com o que se destacou por muitos anos. Em 1927, Hisaya Iwasaki, membro fundador do conglomerado Mitsubishi, resolveu comprar terras no Brasil para que imigrantes japoneses se ambientassem melhor ao novo país. (Fazenda Tozan, 2016).

No período da Segunda Guerra Mundial, a fazenda foi confiscada pelo governo brasileiro por se tratar de uma propriedade de família japonesa. Com o término da guerra, a fazenda voltou aos seus donos, porém enfrentava problemas financeiros. A 
solução foi vender parte da fazenda. Atualmente, a propriedade possui cerca de 900 hectares e ainda se mantém produtiva. Grande parte do café produzido na Fazenda Tozan é destinado ao comércio. Entretanto, a fazenda também mantém atividades turísticas em sua área, como a visita guiada para compreender o processo de produção, entre outros.

\section{Fazenda Jambeiro}

A Fazenda Jambeiro fazia parte da Sesmaria Sete Quedas e começou como grande produtora de cana de açúcar. Posteriormente se transformou em uma grande produtora de café, chegando a contar com 90 mil pés. Com a morte da última proprietária, Maria de Lourdes da Silva Prado, em 1976, a fazenda foi vendida e loteada. Hoje, apenas partes em ruína do casarão e de sua área verde se encontram em pé (Fig. 1 a 4), localizados no meio do bairro que recebeu o seu nome, Parque Jambeiro (Campinas, 2009).

A Fazenda Jambeiro foi tombada pelo CONDEPACC, órgão campineiro responsável pelo patrimônio cultural e histórico, como patrimônio em 1993, em um processo que começou em 1989 e que partiu dos próprios moradores do bairro, que acreditavam que o casarão da fazenda deveria ser protegido por possuir um grande valor histórico.

Atualmente, mesmo tombado, o casarão remanescente da Fazenda Jambeiro encontra-se abandonado e sem uso. Em 2009, a Secretaria de Cultura de Campinas, em conjunto com o CONDEPACC produziu um folheto do patrimônio cultural da cidade, com o intuito de promover os bens tombados para a população, fomentando o turismo local. Entretanto, em visita de campo realizada por Gabriela Barbosa no mês de junho de 2019, percebeu-se que não há por parte da Prefeitura maiores cuidados com o casarão da Fazenda Jambeiro, que se encontra sujo, em ruínas e ocupado por moradores de rua (Figs. 1 a 4 ).

Percebe-se pelas imagens que o estado de conservação do casarão é ruim, o que é bastante preocupante, uma vez que se trata de uma construção importante para a história da região.

\section{Conclusão}

A atividade cafeeira em Campinas se desenvolveu com tanto sucesso por questões principalmente físicas, como relevo, solo, clima e vegetação. $\mathrm{O}$ relevo plano (Campinas recebeu esse nome pela

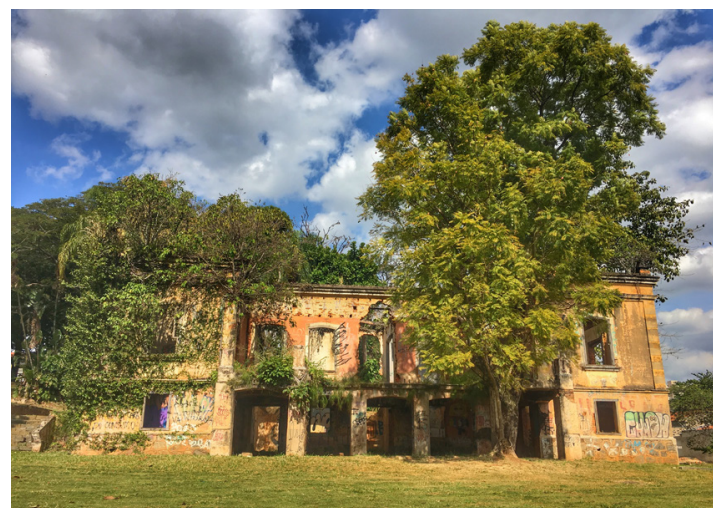

Figura 1. Fachada frontal do casarão da antiga Fazenda Jambeiro. Foto: Gabriela Couto Barbosa, 2019

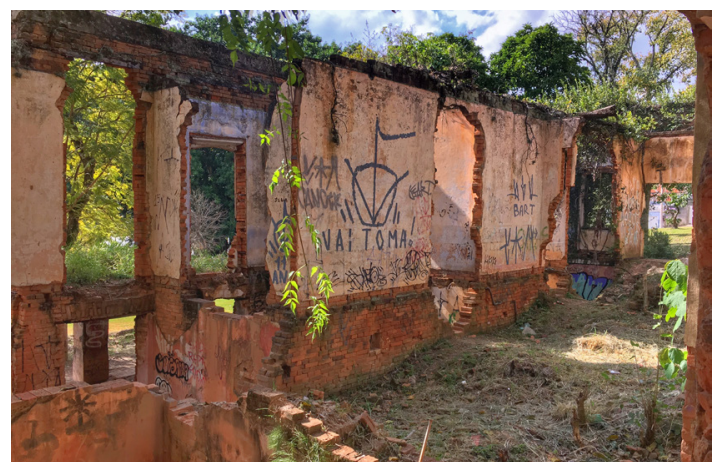

Figura 2. Interior do casarão da antiga Fazenda Jambeiro. Foto: Gabriela Couto Barbosa, 2019

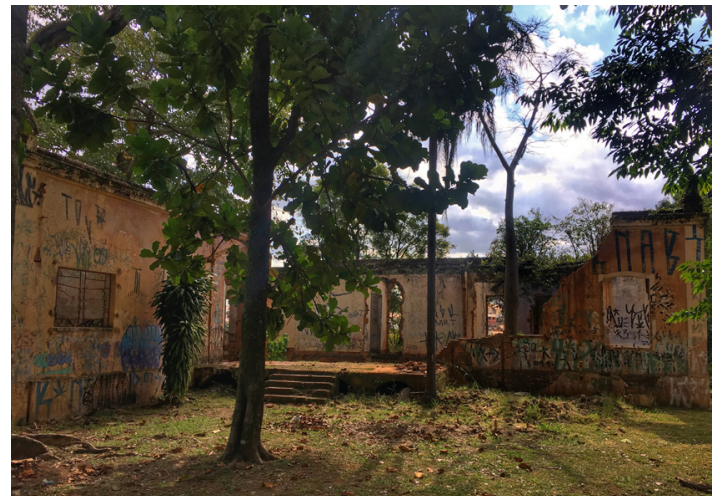

Figura 3. Fundo do casarão da antiga Fazenda Jambeiro. Foto: Gabriela Couto Barbosa, 2019

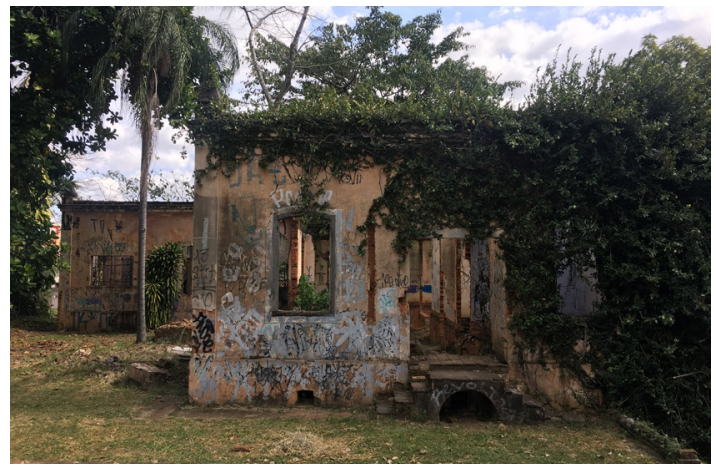

Figura 4. Lateral do casarão da antiga Fazenda Jambeiro. Foto: Gabriela Couto Barbosa, 2019 
grande presença de campos) e a presença de solos como Terra Roxa e Latossolo Roxo, que apresentam uma alta fertilidade e características compatíveis às necessidades da cultura do café, possibilitou para Campinas um grande desenvolvimento desse produto. Além disso, o clima predominantemente tropical, com características de clima tropical de altitude (quase subtropical) permite que seja possível um planejamento em relação aos períodos secos e chuvosos.

Em relação ao processo de refuncionalização de espaços, foi possível constatar que não é um fenômeno incomum, principalmente quando se trata do turismo. Espaços que originalmente serviram para outras atividades podem se tornar atrativos turísticos.

Entretanto, há de se considerar que a apropriação de tais espaços, se não realizada com cautela, pode prejudicar a manutenção da memória e da história de tais locais. As fazendas de café, por exemplo, proporcionam uma imersão do visitante ao período áureo do café no Brasil.

Em Campinas, o café desempenhou papel fundamental para o desenvolvimento econômico e social do Estado de São Paulo, e - por que não dizer? - do Brasil; por isso, sua história merece destaque. Assim, fazendas de café constituem excelentes ferramentas para a divulgação da história do café, pois proporcionam uma experiência "in situ". Além disso, há a possibilidade de divulgação da ciência e da tecnologia empregadas no processo produtivo, uma vez que se podem abordar aspectos voltados, por exemplo, às Geociências, como solo, relevo, clima etc., às engenharias, às ciências sociais e econômicas, assim como aspectos voltados ao turismo e à agricultura. Conclui-se, por fim, que a refuncionalização de fazendas de café pelo turismo pode ser considerada ferramenta bastante importante para sua preservação e conservação das atuais e antigas fazendas de café em Campinas (SP), assim como nas demais regiões produtoras ou antigas regiões produtoras do Brasil.

\section{Referências}

Argollo Ferrão, A. M. de. (2004). Arquitetura do Café. Campinas: Unicamp; São Paulo: Imprensa Oficial do Estado de São Paulo.

Argollo Ferrão, A. M. de. (2015). Arquitetura do Café. 2a. ed., Campinas: Editora da Unicamp.
Beni, M. C. (2004). Análise Estrutural do Turismo. 10 ed. São Paulo: Editora SENAC.

Benincasa, V. (2007). Fazendas Paulistas: arquitetura rural no ciclo cafeeiro. São Carlos. EESC/USP.

Brasil, Ministério do Turismo (MTur). (2014). Marcos Conceituais. Brasília, DF: MTur. URL: http://www. turismo.gov.br/sites/default/turismo/o_ministerio/ publicacoes/downloads_publicacoes/

Caetano, M. (2006). Estudo das práticas alimentares dos turistas: uma contribuição metodológica para o planejamento turístico e o fortalecimento do agronegócio. Campo Grande: Depto. Economia e Administração, Universidade Federal de Mato Grosso do Sul. 91p. (Dissert. Mestrado, Agronegócios).

Campinas, Para Todos. (2009). Antiga Fazenda Jambeiro: Conjunto arquitetônico e ambiental. Campinas: Folheto do Patrimônio Cultural de Campinas.

Fazenda Tozan. (2016). História da imigração japonesa em Campinas. Cidade e Cultura, 2016. URL: https:// www.cidadeecultura.com/fazenda-tozan-historia-da-imigracao-japonesa-em-campinas/ Acesso jun.2019.

Fazenda das Cabras. (2011). Fazenda das Cabras. Campinas, 2011. URL: www.fazendadascabras.com.br. Acesso jun.2019.

Martin, Davi. (2019). Entrevista sobre fazendas de café voltadas ao turismo em Campinas. Agosto de 2019. Entrevista concedida a Gabriela Couto Barbosa.

Organização Mundial do Turismo (OMT). (2016). Actualización de las Recomendaciones sobre estadísticas de turismo OMT-ONU. Serie M No. 83 (1994). 27p. URL: https://unstats.un.org/unsd/statcom/doc00/ m83note-s.pdf. Acesso 10.dez.2016.

Ramos, P., \& Piacente, F. J. (2016). O Instituto Agronômico de Campinas: sua criação, importância e um pouco de sua história. Revista Brasileira de Inovação, 15(2), 365-392. doi: 10.20396/rbi. v15i2.8649134.

Rodrigues, H. L., Dias, F. D., \& Teixeira, N. C. (2015). A origem do café no Brasil: a semente que veio pra ficar. Revista Pensar Gastronomia. 1(2). 22 p. URL: http://revistapensar.com.br/gastronomia/pasta_ upload/artigos/a44.pdf.

Rufino, J. L. S. (2006). Programa Nacional de Pesquisa e Desenvolvimento do Café: antecedentes, criação e evolução / José Luís dos Santos Rufino. Brasília, DF. Embrapa Café. 348p. (Embrapa Informação Tecnológica, 2006).

Silva, A. P. (2006). Engenhos e fazendas de café em Campinas (séc. XVIII - séc. XX). São Paulo. Anais do Museu Paulista. 14(1), 81-119.

World Travel and Tourism Council (WTTC). (2019). Annual research: key highlights. The World Travel and Tourism Council website. URL: https://wttc.org/ Research/Economic-Impact. 